\title{
Researching the Determinants of Vulnerability to HIV among Adolescents
}

\author{
Kelly K. Hallman*
}

Adolescents in sub-Saharan Africa are exposed to diverse influences regarding lifestyles that are healthy and appropriate - running the gamut from their peers, the norms of community elders, to those of sophisticated global media campaigns. Although a multitude of programmes focusing on individual behaviour change among adolescents (aged 10-19) and young people (aged 15-24) have been imported from the North, the merit of such approaches in curbing the HIV/AIDS epidemic is questionable. Even those that are more home grown and attempt to incorporate traditional values have not proven effective enough. The large number of orphans and vulnerable children (OVC) programmes, on the other hand, consist primarily of mitigation approaches for young children (housing, food and education assistance) (Foster et al. 2005). Most do not recognise that the majority of orphans and children whose parents are HIV-positive or AIDS-unwell are in fact adolescents (UNAIDS 2004a), and have a great need for information and skills on sexual and reproductive health and development. These topics are frequently omitted from OVC programmes, as the subjects are culturally sensitive, awkward for implementers to deliver, and avoided by some donors. Images of innocent orphans needing charity do not 'sync' with the fact that these children are also emerging sexual beings. The links among OVC status, HIV risk and the need for social and economic support have not been made clearly enough. The young people who reside in households most affected by AIDS - which because of AIDS are also frequently poor and socially disconnected - are in fact the very same young persons for whom vulnerability to HIV infection is also high. Only a few recent research efforts (discussed below) make this crucial link. This article brings together research findings to help elucidate these connections. Evidence on the gendered associations among poverty status, orphanhood, social capital and HIV risk for young people in subSaharan Africa will be highlighted and its implications discussed.

\section{Young people, HIV and gender in sub-Saharan Africa}

Of the estimated 39 million people living with HIV/AIDS worldwide, nearly one-third are aged 15-24 years (UNAIDS 2006). This group accounts for two-thirds of newly infected individuals in developing countries (UNAIDS 2004b). Over 63 per cent of persons living with HIV/AIDS reside in sub-Saharan Africa (UNAIDS 2006). Among those who have died of AIDS, approximately half became infected as 15-24 year olds (UNAIDS 2006).

In sub-Saharan Africa, 75 per cent of young people living with HIV are female (UNAIDS 2006).

Population-based surveys from seven countries in this region indicate that young females are 2.7 times more likely to be living with HIV than their same-age male peers (WHO/AFRO 2002). A nationally representative survey in South Africa (Shisana et al. 2005) found that HIV prevalence among young people was 16.9 per cent for females and 4.4 per cent for males - a nearly four-fold difference. The gendered ratio of new infections among this age group was even more extreme at 8:1. Rates also varied significantly by locality type, with youths residing in urban informal settlements (slums) and rural formal settings (which are heavily populated by male migrant workers) having greatly elevated risk. While the report did not describe HIV prevalence for 
young people by socioeconomic status per se, locality type serves as a rough proxy. The overall portrait indicates that in South Africa economically disadvantaged young black females residing in KwaZulu-Natal are at particularly high risk for HIV.

\section{Poverty}

Research exploring the effects of absolute and relative socioeconomic disadvantage on adolescent HIV risk in sub-Saharan Africa shows that being at the lower end of the socioeconomic spectrum is associated with a higher risk of unsafe sexual encounters among adolescents, especially, but not exclusively, for females. Using 1996 data from urban Kenya, Hargreaves et al. (2002) found that young women in the lowest socioeconomic status (SES) tercile had significantly younger age at first intercourse than those in the two higher SES terciles. In a gender-pooled analysis, Ruenge (2003) shows that relative socioeconomic disadvantage increases the odds of early sexual debut and of having multiple sex partners for young Cameroonians. In South Africa, Whitefield (1999) found that violence within the relationships of secondary school students is more common among those who are poorer. In urban Mozambique, Machel (2001) showed that female secondary school students in a working-class neighbourhood were much more likely to have received material support from their sexual partners than girls attending a middle-class secondary school.

Poverty and lack of family financial support are cited as primary reasons for young women to trade sex for goods or favours or to be involved in sexual relationships that involve financial support (Adams and Marshall 1998; Kelly and Parker 2000). In urban market-based settings, the need for cash increases the chances of selling sex (Gage 1998). Anecdotal evidence suggests that poverty and austerity measures have caused young women and mothers to turn to sexual transactions in order to obtain cash (Cohen 1998). Hunter (2002), in a study in rural KwaZuluNatal, argues that it is the taken-for-granted nature of transactional sex that is the most crucial and poorly understood factor fuelling the spread of HIV, and that gendered material inequalities provide the basis for such transactions. He asserts that masculinities constructed through historically rooted practices and structural factors - are also central.

HIV prevalence in Africa does not directly correspond with per capita income levels. In fact, countries with greater average income have higher HIV levels. What is not discussed, however, is that countries with high HIV prevalence also have extreme levels of income inequality. All seven countries in the world with adult HIV prevalence of 20 per cent or greater (all located in southern and eastern Africa) have very high Gini indices (UNDP 2006). Using a random sample of young people in KuaZulu-Natal, Hallman (2005) found that for both females and males, residing in a lower wealth household was associated with younger age at sexual debut and lower odds of discussing safe sex practices with recent sexual partners. Among females only, low relative wealth was correlated with lower chances of using a condom at last sex, and higher odds of exchanging sex for money or gifts, experiencing non-consensual sex, and having multiple sexual partners in the year before the survey. Using these same data but limited to the sub-sample of 14-18-year-olds and with controls for social capital added to the list of sociodemographic covariates, Hallman (2008a) shows that household wealth (number of physical assets) had a statistically significant inverse association with female risk behaviours, but household income/expenditure poverty did not. Greater relative household wealth was positively associated for adolescent females with later age at sexual debut and lower chances of ever having experienced non-consensual sex. Using data on 15-49 year olds (not age disaggregated), Mishra et al. (2007) show that while in some countries wealth and HIV status are positively related in bivariate comparisons, in multivariate analysis with controls added, relative wealth (quintile index) and HIV prevalence are not statistically significantly related. Wojcicki's (2005) review of the relationship between SES and HIV in adult women in Southern, Central and Eastern Africa shows mixed evidence. She finds overall that increasing women's access to resources may have initially little effect on risk-taking behaviours, but in southern Africa where per capita incomes are higher and inequalities are greater, increasing female SES may decrease female HIV risk. She also asserts that the male sexual partner's SES may in fact be a stronger predictor of female HIV serostatus than female pre-partnership SES.

\section{Orphanhood}

Although child fosterage has a long history in Africa, $\mathrm{HIV}$ is altering the rates and nature of such arrangements (Madhavan 2004). AIDS-related mortality among prime-age adults in most countries 
in the region is on the rise, and hence, levels of orphanhood are increasing (UNICEF 2007). This situation is likely to contribute to the vulnerability of already complex family arrangements (Foster 2000). Parental death is recognised as one of the most stressful life events a child or adolescent can endure - and it increases the risk for behavioural problems (American Psychiatric Association 1994). Research in the USA has demonstrated that children

experiencing parental death have unusually high rates of depression (Siegel et al. 1992; West et al. 1991), with more than one-third meeting criteria for psychiatric disorders (Sanchez et al. 1994; Siegel et al. 1996). Furthermore, many engage in behaviours such as early and unprotected sex to a higher degree than non-parentally bereaved adolescents (Hudis 1995). These risks may be exacerbated when parental morbidity and subsequent death are characterised by AIDS symptoms, as fear of disclosure of the disease often trumps the need for social support and leads to social isolation. This can be particularly damaging to the healthy development of adolescents during a life stage when parental guidance is necessary for proper social and emotional maturation (Lester et al. 2006). Positive parent-child interaction has been linked to delays in the onset of sexual activity and lower rates of sexual risk taking in both US minority populations (Miller et al. 1999; O'Sullivan et al. 1999) and in developing countries (Babalola et al. 2005; Marques and Ebrahim 1991). In the absence of one or both parents, particularly the same sex parent, positive role modelling and effective communication about sexuality and sexual behaviours is often missing (Perrino et al. 2000). Psychosocial support, monitoring and supervision of adolescent activities are also lower (Barber et al. 2005). Parental death has been shown to lead to low perceived selfefficacy among young people, which is associated with feeling a lack of control over one's sexual health and higher sexual risk-taking behaviours (Gregson et al. 2004). Cluver and Gardner (2007) review the mental health of children orphaned by AIDS and conclude that outside of the USA, there is very little evidence of higher rates of behavioural problems among AIDS-affected children, but that internalising problems are common among this group in subSaharan Africa. A study with 1,050 adolescents in South Africa that used validated psychological instruments found that AIDS-orphaned children had rates of clinic-level psychiatric disorders well above non-orphans, other orphans and Western norms (Cluver and Gardner 2007).
Several recent studies have explored the relationship between orphanhood and HIV risk among young people in Southern Africa. A study in eastern Zimbabue (Gregson et al. 2005) indicated that orphaned females aged 15-18 years, especially those who had lost a mother, had significantly higher HIV infection rates than non-orphaned females; orphan status was not associated with higher rates of HIV infection among males, where the sample was limited to 17-18 year olds. Another study in Zimbabue (Birdthistle et al. 2008) of girls aged 15-19 showed that orphaned never-married girls were more likely than non-orphaned girls to have ever been pregnant and to test positive for HIV and HSV-2 (herpes simplex virus). Although not a population-based study, a review of HIV and child labour conducted by Rau (2003) in Tanzania and Zambia finds that the majority of young commercial sex workers surveyed were in fact orphans. Thurman et al. (2006) investigated the effect of an orphan status indicator on sexual debut among 14-18 year olds in KwaZulu-Natal and found that orphans were almost 1.5 times more likely to have already had sex than non-orphans. The analysis controlled for, but did not stratify by gender. Using a nationally representative survey of young people aged 15-24 in South Africa collected in 2003, Operario et al. (2007) studied the association between orphanhood (also using an indicator of one or both parents deceased) and (a) sexual behaviours, and (b) HIV sero-status. Adjusting for other sociodemographic factors, parental death among females was significantly associated with HIV-positive status, ever having had sex, and having one or more sexual partners in the year before the survey. Among males, parental death was significantly associated with ever having had sex and having unprotected sex at the last episode.

\section{Hallman (2004) investigated the effects of orphan} type on the sexual experiences of 14-24-year-olds in KwaZulu-Natal and found, after adjusting for other sociodemographic factors, that female and male paternal orphans debuted earlier sexually, female paternal orphans had older sex partners, and male paternal orphans had lower odds of practising secondary abstinence (refraining from intercourse, though sexually active in the past). Female and male maternal orphans had lower chances of discussing safe sexual practices with their most recent sexual partner. With data from the same survey, but focusing exclusively on 14-18 year olds, Hallman (2008a) finds that orphanhood is more highly 
associated with male than with female sexual risk behaviours. Double-orphaned male adolescents were more likely to have ever had sex compared with nonorphans and their first sexual experiences were much more likely to be non-consensual. Paternal orphans, on the other hand, were less likely than non-orphans to have had multiple sexual partners in the year before the survey. Among young males who had had sex in the year before the survey, maternal orphans were less likely than non-orphans to have used a condom at their last sexual encounter. Using longitudinal data from KwaZulu-Natal, Hallman (2008b) examines the effect of orphan type (maternal, paternal, or double) on the sexual debut of young aged 14-22 at baseline. She finds that, other factors being equal, losing a mother or a father in the two years between survey rounds hastens sexual initiation for girls. Among boys, the death of a father, but not a mother, was associated with greater odds of sexual debut between survey rounds.

Other research from Africa investigates the consequences of parental illness and death on education - mainly of primary school age children and finds that maternal death has large and persistent effects on school attendance and educational attainment. This is relevant for HIV risk in light of Lloyd's (2007) cross-country results from Demographic and Health Survey (DHS) data showing that non-enrolled adolescent girls are more vulnerable to sexual and reproductive health risks. Parental morbidity and death have the potential to affect not only child education, but also lessen the ability of families to provide the protective support structures to adolescents as they mature sexually. Young people may have to take on extra care-giving roles and may consequently perform poorly in school, drop out, or be withdrawn from school altogether (Hartell and Chabilall 2005). Both Ainsworth et al. (2005) and Evans and Miguel (2007) find that reductions in school attendance occurred before the death of a parent.

\section{Social capital}

Another structural factor likely to influence young people's sexual health and development is social capital. The studies on this topic focus almost exclusively on voluntary membership in community groups and show mixed and inconclusive results, with significant gender differences. $A$ study by Gregson et al. (2004) in Zimbabwe among young women aged 15-24 revealed that membership in various types of voluntary community groups had a range of associations with being HIV sero-negative. With other factors controlled for, young women with secondary education who belong to a (wellfunctioning) community group had lower HIV prevalence than those who did not belong to such a group. This was particularly the case for membership in youth, women's and church groups. For women without any secondary education, on the other hand, HIV avoidance was, while positively related to youth group membership, in fact negatively related to membership in political parties. Using data from KwaZulu-Natal, Kaufman et al. (2004) assessed the influence on sexual risk of voluntary community group membership (sports, religious, and an aggregated 'other types' category) and found that in communities where young people had high rates of participation in sports activities, girls had decreased odds of recent sexual activity, but boys had significantly lower chances of having used a condom at last sex. In a different part of South Africa, Campbell et al. (2002) examined the association between adult and adolescent membership in voluntary organisations, HIV-related risk behaviours and HIV sero-status. They find a range of significant results, varying by age and gender, but not all were in the direction hypothesised. Young women (aged 15-24) belonging to sports clubs were less likely to be HIV-positive and more likely to use condoms with casual partners than non-members. Among members of voluntary savings clubs (stokvels), young females were more likely to have a casual partner, and both young men and women (aged 15-24) were more likely to drink alcohol than non-members. Camlin and Snow (2008) use the Cape Area Panel Study (CAPS) from South Africa to assess the effects of voluntary community group membership on condom use at first sex and condom use at most recent sex among 14-22 year olds in Cape Town. Controlling for other factors, their results (though regrettably not gender stratified) reveal that belonging to a voluntary community group is associated with higher odds of condom use at both first sex and last sex.

Hallman (2008a) examines the effects of individual voluntary group membership and community level trust and reciprocity on the gendered sexual health behaviours of adolescents in KuaZulu-Natal. Social cohesion was measured using responses to questions posed to each adolescent about her/his perceptions of trust and reciprocity in her/his community. 
Summary statistics show that boys generally tend to report feeling more 'included' in their communities than do girls. Boys are particularly more likely to report having many friends in the community, that they feel safe moving about in the community, and that trust among neighbours is high. These individual trust and reciprocity measures, and then a constructed index, were used in alternative regression specifications. With the index, a more cohesive community was associated with lower chances of male first sexual experience being nonconsensual. When trust and reciprocity measures were entered as individual variables, a high perceived level of crime was correlated with greater chances of female first sex being non-consensual. Furthermore, greater levels of perceived trust among neighbours were correlated with lower odds of girls experiencing non-consensual sex. Having more friends was associated with lower odds of young male first sex being non-consensual (possibly through protection from coercion by older males), while a high level of crime was associated with lower chances of having multiple sexual partners in the year before the survey.

Although no other studies from sub-Saharan Africa were found to compare these results, significant relationships between social capital and adolescent HIV and sexual health risk behaviours have been documented in the USA. Browning et al. (2004) study the effects of community cohesion on adolescent sexual behaviours using multi-level data from Chicago. With a set of survey questions similar to those in the Hallman (2008a) study, this study revealed that higher levels of neighbourhood trust and reciprocity - referred to by the authors as 'collective efficacy' - contributed to a delay of sexual onset among adolescents. The reasoning provided was that neighbourhood structural disadvantage (economic insecurity, insecure housing tenure, and a high proportion of recent immigrants) inhibits the formation of social capital, which in turn reduces the ability of local residents to mobilise around neighbourhood goals, including the effective supervision and socialisation of children and teenagers. This analysis did not disaggregate adolescents by gender, but is consistent with that of Youngblade et al. (2006), who found that community investment in social capital in Florida predicted lower levels of risky sexual behaviours among adolescents.

In the study of adolescents in KwaZulu-Natal,
Hallman (2008a) also explored the effects of voluntary community membership, finding that boys were more likely than girls to belong to voluntary groups. One-third of female and one-quarter of male respondents did not belong to any group. Males were most likely to belong to a sports group, whereas female involvement was greatest in religious groups - according to Mensch et al. (1998), both of these would be indications of gendered social role norms during adolescence. Belonging to a voluntary community group had greater effects on girls' than boys' risks. Multivariate findings suggest that membership in a variety of groups was associated with lower risk for females. Girls in sports, study and religious groups had later age of sexual onset; those in savings, sports and religious groups were less likely to have experienced non-consensual sex; those in sports groups had 11 times higher likelihood of using a condom at last sex than girls not in a sports group. The only significant group factor for males was membership of a dance, music or choir group, and this was associated with greater odds of early sexual debut. While these results are instructive, it is important to consider the possibility of mediating factors between inclusion in organised groups and protection from HIV - such as parental encouragement, having enough free time from domestic responsibilities, not being stigmatised, etc.

\section{Discussion}

Overall, the sum of evidence presented indicates that among young people in sub-Saharan Africa, poor girls, orphaned girls and boys, and socially excluded girls are the most likely to be subject to social environments that render them vulnerable and engender high-risk sexual behaviours. Specifically:

- Orphaned adolescents display higher sexual risk taking, which provides a strong argument for linking OVC programmes with adolescent prevention.

- This sexual health risk to orphans is gendered both by adolescent sex and by the sex of the deceased parent. Both social protection and adolescent prevention programmes need to be carefully tailored to the gender of the orphans themselves and be sensitive to whether the parent lost is of the same or opposite sex.

- Adolescent girls affected by both orphaning and poverty are particularly vulnerable and at risk. This suggests that social protection for poor families should be concerned about orphans - particularly 
girls - and be linked to prevention programmes to empower them in terms of sexual awareness, control, and economic and social asset building.

- The vulnerability of girls is moderated and mitigated by social participation, inclusion in groups (which might be compromised by HIV stigma), and more cohesive neighbourhood environments. This calls for going beyond a simple focus on strengthening families economically, for a more structural analysis and for social protection and prevention to link to the extra-household sphere - particularly as the transition to adulthood involves a process of gradually leaving home.

Given that young people constitute a high proportion of the African population, programmes need to be designed to address these specific vulnerabilities and effectively target appropriate gender, age, and sociodemographic subpopulations most in need. Current programmes are either not reaching, or if reaching, are not providing sufficient social, health and economic protection strategies for these groups of young people. Interventions must

\section{Note}

* The author would like to thank Hannah CarterMenn for excellent research and editorial assistance. Eva Roca and Emmanuelle St Jean also provided valuable research assistance. The work was supported by funding from the UK

\section{References}

Adams, H. and Marshall, A. (1998) 'Off-target Messages of Poverty, Risk and Sexual Rights', Agenda 39: 87-92

Ainsworth, M.; Beegle, K. and Godlike, K. (2005) 'The Impact of Adult Mortality and Parental Deaths on Primary Schooling in North-Western Tanzania', Journal of Development Studies 41.3: 412-39

American Psychiatric Association (1994) Diagnostic and Statistical Manual of Mental Disorders (4th edn, revised), Washington DC: American Psychiatric Association

Babalola, S.; Tambashe, B.O. and Vondrasek, C. (2005) 'Parental Factors and Sexual Risk-Taking among Young People in Côte d'lvoire', African Journal for Reproductive Health 9.1: 49-65

Barber, B.K.; Stolz, H.E. and Olsen, J.A. (2005) 'Parental Support, Psychological Control, and adopt a more ecological approach and focus on the gendered economic, social, political and cultural determinants of sexual practices (Bruce and Hallman 2008). They must recognise that certain sexual behaviours - which may be viewed as negative by outsiders and/or public health specialists, and, which may bring negative health consequences in the longrun - are frequently not subject to choice (especially among girls). Even where choice is not the constraint and behaviours are consensual, interventions must recognise that these may bring great social, economic and psychological benefits to young persons, which outweigh perceived health risks. Sexuality is a natural aspect of the transition to adulthood and adolescent programming intended to address HIV risk should therefore offer stronger forms of social and economic support in order to build individual, family and community resilience for responding to HIV and AIDS, including coping with the loss of a parental figure or dealing with social and economic stresses from illness and stigma (DiClemente et al. 2005; Campbell et al. 2005; Hsu et al. 2002)

Department for International Development (DFID) and the Joint Learning Initiative on Children and AIDS (JLICA). The views expressed are not necessarily those of DFID or JLICA.

Behavioural Control: Assessing Relevance Across Time, Method, and Culture', Monographs of the Society for Research in Child Development 70.4: 1-137

Birdthistle, I.; Floyd, S.; Machingura, A.; Mudziwapasi, N.; Gregson, S. and Glynn, J.R. (2008) 'From Affected to Infected? Orphanhood and HIV Risk among Female Adolescents in Urban Zimbabue', AIDS 22: 759-66

Browning, C.R.; Leventhal, T. and Brooks-Gunn, J. (2004) 'Neighborhood Context and Racial Differences in Early Adolescent Sexual Activity', Demography 41.4: 697-720

Bruce, J. and Hallman, K. (2008) 'Reaching the Girls Left Behind', Gender and Development 16.2: 227-45

Camlin, C. and Snow, R. (2008) 'Parental Investment, Club Membership and Youth Sexual Behavior in Cape Town', Health Education and Behavior 35.4: 522-40 
Campbell, C.; Williams, B. and Gilgen, D. (2002) 'Is Social Capital a Useful Conceptual Tool for Exploring Community Level Influences on HIV Infection? An Exploratory Case Study from South Africa', AIDS Care 14.1: 41-54

Campbell, C.; Foulis, C.A.; Maimane, S. and Sibiya, Z. (2005) 'The Impact of Social Environments on the Effectiveness of Youth Prevention: A South African Case Study', AIDS Care 17.4: 471-8

Cluver, L. and Gardner, F. (2007) 'Mental Health of Children Orphaned by AIDS: A Review of International and Southern African Research', Journal of Child and Adolescent Mental Health 19.1: $1-17$

Cohen, D. (1998) Poverty and HIV/AIDS in SubSaharan Africa, UNDP HIV and Development Programme, Issues Paper 27, New York: United Nations Development Programme (UNDP)

DiClemente, R. J.; Salazar, L.F;; Crosby, R.A. and Rosenthal, S.L. (2005) 'Prevention and Control of Sexually Transmitted Infections among Adolescents: The Importance of a Socio Ecological Perspective A Commentary', Public Health 119.9: 825-36

Evans, David K. and Edward, Miguel (2007) 'Orphans and Schooling in Africa: A Longitudinal Analysis', Demography 44.1: 35-57

Foster, G. (2000) 'The Capacity of the Extended Family Safety Net for Orphans in Africa', Psychology, Health and Medicine 5.1: 55-63

Foster, G.; Levine, C. and Williamson, J. (eds) (2005) A Generation at Risk: The Global Impact of HIV/AIDS on Orphans and Vulnerable Children, New York: Cambridge University Press

Gage, A.J. (1998) 'Sexual Activity and Contraceptive Use: The Components of the Decision-making Process', Studies in Family Planning 29.2: 154-66

Gregson, S.; Terceira, N.; Mushati, P.; Nyamukapa, C. and Campbell, C. (2004) 'Community Group Participation: Can it Help Young Women to Avoid HIV? An Exploratory Study of Social Capital and School Education in Rural Zimbabwe', Social Science and Medicine 58.11: 2119-32

Gregson, S.; Nyamukapa, C.A.; Garnett, G.P.; Wambe, M.; Lewis, J.J.C.; Mason, P.R.; Chandiwana, S.K. and Anderson, R.M. (2005) 'HIV Infection and Reproductive Health in Teenage Women Orphaned and Made Vulnerable by AIDS in Zimbabue', AIDS Care 177: 785-94

Hallman, K. (2008a) 'Social Exclusion: The Gendering of Adolescent HIV Risk in South Africa', in J. Klot and V. Nguyen (eds), The Fourth Wave: An Assault on Women - Gender, Culture and HIV in the 21st
Century, Social Science Research Council and UNESCO, under review

Hallman, K. (2008b) 'Orphanhood Type and Sexual Debut: A Panel Study from KwaZulu-Natal, South Africa', Economic Development and Cultural Change, under review

Hallman, K. (2005) 'Gendered Socioeconomic Conditions and HIV Risk Behaviours among Young People in South Africa', African Journal of AIDS Research 4.1: 37-50

Hallman, K. (2004) 'Socioeconomic Disadvantage and Unsafe Sexual Behaviours of Young Women and Men in South Africa', Policy Research Division Working Paper 190, New York: Population Council, www. popcouncil.org/publications/wp/wplist.html (accessed 29 July 2008)

Hargreaves, J.R.; Morison, L.A.; Chege, J.; Rutenburg, N.; Kahindo, M.; Weiss, H.A.; Hayes, R. and Buvé, A. (2002) 'Socioeconomic Status and Risk of HIV Infection in an Urban Population in Kenya', Tropical Medicine and International Health 7.9: 793-802

Hartell, C.G. and Chabilall, J.A. (2005) 'HIV/AIDS in South Africa: A Study of the Socio Educational Development of Adolescents Orphaned by AIDS in Child-headed Households', International Journal of Adolescence and Youth 12.3: 213-29

Hudis, J. (1995) 'Adolescents Living in Families with AIDS', in S. Geballe, J. Gruendel, and W. Andiman (eds), Forgotten Children of the AIDS Epidemic, New Haven, CT: Yale University Press: 83-94

Hunter, M. (2002) 'The Materiality of Everyday Sex: Thinking Beyond "Prostitution"', African Studies 61.1: 99-120

Hsu, L.N.; du Guerny, J. and Marco, M. (2002) Communities Facing the HIV/AIDS Challenge: From Crisis to Opportunity, From Community Vulnerability to Community Resilience, Bangkok: United Nations Development Programme (UNDP), South East Asia HIV and Development Programme

Kaufman, C.E.; Clark, S.; Manzini, N. and May, J. (2004) 'Communities, Opportunities, and Adolescents' Sexual Behavior in KwaZulu-Natal, South Africa', Studies in Family Planning 35.4: 261-74

Kelly, K. and Parker, P. (2000) Communities of Practice: Contextual Mediators of Youth Response to HIV/AIDS, Pretoria: Department of Health, Sentinel Site Monitoring and Evaluation Project for the Beyond Awareness Campaign

Lester, P.; Rotheram-Borus, M.J.; Lee, S.J.; Comulada, S.; Cantwell, S.; Wu, N. and Lin, Y.Y. (2006) 'Rates and Predictors of Anxiety and Depressive 
Disorders in Adolescents of Parents with HIV', Vulnerable Children and Youth Studies 1.1: 81-101

Lloyd, C.B. (2007) The Role of Schools in Promoting Sexual and Reproductive Health among Adolescents in Developing Countries, Poverty, Gender, and Youth Working Paper 6, New York: Population Council

Machel, J.Z. (2001) 'Unsafe Sexual Behaviour among Schoolgirls in Mozambique: A Matter of Gender and Class', Reproductive Health Matters 9.17: 82-9

Madhavan, S. (2004) 'Fosterage Patterns in the Age of AIDS: Continuity and Change', Social Science and Medicine 58.7: 1443-54

Marques, N.M. and Ebrahim, G.J. (1991) 'The Antecedents of Adolescent Pregnancy in a Brazilian Squatter Community', Journal of Tropical Pediatrics 37.4: 194-8

Mensch, B.S.; Bruce, J. and Greene, M.E. (1998) The Uncharted Passage: Girls' Adolescence in the Developing World, New York: Population Council

Miller, K.E.; Sabo, D.F.; Farrell, M.P.; Barnes, G.M. and Melnick, M.J. (1999) 'Sports, Sexual Behavior, Contraceptive Use, and Pregnancy among Female and Male High School Students: Testing Cultural Resource Theory', Sociology of Sport Journal 16.4: 366-87

Mishra, V.; Assche, S.; Greener, R.; Vaessen, M.; Hong, R.; Ghys, P.D.; Boerma, J.T.; Van Assche, A.; Khan, S. and Rutstein, S. (2007) 'HIV Infection does not Disproportionately Affect the Poorer in SubSaharan Africa', AIDS 21 suppl. 7: S17-28

Operario, D.; Pettifor, A.; Cluver, L.; MacPhail, C. and Rees, H. (2007) 'Prevalence of Parental Death among Young People in South Africa and Risk for HIV Infection', Journal of Acquired Immune Deficiency Syndromes 44.1: 93-8

O'Sullivan, L.F.; Jaramillo, B.M.S.; Moreau, D. and Meyer-Bahlburg, H.F.L. (1999) 'Mother Daughter Communication about Sexuality in a Clinical Sample of Hispanic Adolescent Girls', Hispanic Journal of Behavioral Sciences 21: 447-69

Perrino, T.; Gonzalez-Soldevilla, A.; Pantin, $\mathrm{H}$. and Szapocznic, J. (2000) 'The Role of Families in Adolescent HIV Prevention: A Review', Clinical Child and Family Psychology Review 3.2: 81-96

Rau, B. (2003) HIV/AIDS and Child Labour. A State-ofthe Art Review with Recommendations for Action, Synthesis Report, Paper 6, Geneva: International Labour Organization, International Programme on the Elimination of Child Labour

Rwenge, M.J.R. (2003) 'Poverty and Sexual Risk Behaviour among Young People in Bamenda, Cameroon', African Population Studies 18.2: 91-104
Sanchez, L.; Fristad, M.; Weller, R.A. and Weller, E.B. (1994) 'Anxiety in Acutely Bereaved Prepubertal Children', Annals of Clinical Psychiatry 6: 39-43

Shisana, O.; Rehle, T.; Simbayi, L.C.; Parker, W.; Zuma, K.; Bhana, A.; Connolly, C.; Jooste, S. and Pillay, V. (eds) (2005) South African National HIV Prevalence, HIV Incidence, Behavior and Communication Survey, 2005, Cape Town: Human Sciences Research Council Publishers (HSRC) Press

Siegel, K.; Karus, D. and Raveis, V.H. (1996) 'Adjustment of Children Facing the Death of a Parent Due to Cancer', Journal of the American Academy of Child and Adolescent Psychiatry 35: 442-50

Siegel, K.; Mesagno, F.P.; Karus, D.; Christ, G.; Banks, K.B. and Moynihan, R. (1992) 'Psychosocial Adjustment of Children with a Terminally III Parent', Journal of the American Academy of Child and Adolescent Psychiatry 31: 327-33

Thurman, T.R.; Brown, L.; Richter, L.; Maharaj, P. and Magnani, R. (2006) 'Sexual Risk Behaviour Among South African Adolescents: Is Orphan Status a Factor?', AIDS Behavior 10: 627-35

UNAIDS (Joint United Nations Programme on HIV/AIDS) (2006) Report on the Global AIDS Epidemic: A UNAIDS 10th Anniversary Special Edition, Geneva: UNAIDS

UNAIDS (2004a) Children on the Brink 2004: A Joint Report of New Orphan Estimates and a Framework for Action, Washington DC: USAID; New York: UNICEF; Geneva: UNAIDS

UNAIDS (2004b) World AIDS Campaign 2004: Women, Girls, HIV and AIDS, Strategic Overview and Background Note, February, Geneva: UNAIDS UNDP (2006) Beyond Scarcity: Power, Poverty and the Global Water Crisis, Human Development Report 2006, New York: United Nations Development Programme (UNDP)

UNICEF (2007) The State of the World's Children 2008, New York: UNICEF

West, S.G.; Sandler, I.; Pillow, D.R.; Baca, L. and Gersten, C. (1991) 'The Use of Structural Equation Modeling in Generative Research: Toward the Design of a Preventive Intervention for Bereaved Children', American Journal of Community Psychology 19: 459-80

Whitefield, V.J. (1999) 'A Descriptive Study of Abusive Dating Relationships among Adolescents', MA thesis, University of Cape Town, South Africa

WHO/AFRO (2002) Regional Office for Africa 2002: HIV/AIDS Epidemiological Surveillance Update for 
the WHO African Region, Brazzaville: Democratic Republic of Congo

Wojcicki, J.M. (2005) 'Socioeconomic Status as a Risk Factor for HIV Infection in Women in East,

Central, and Southern Africa: A Systematic

Review', Journal of Biosocial Science 37: 1-36
Youngblade, L.M.; Curry, L.A.; Novak, M.; Vogel, B. and Shenkman, E.A. (2006) 'The Impact of Community Risks and Resources on Adolescent Risky Behavior and Health Care Expenditures', Journal of Adolescent Health 38.5: 486-94 